\title{
LEADing the Way: Perceptions of Self-Advocate Educators (SAEs) for Law Enforcement
}

\author{
Schoenbrodt $\mathrm{L}^{1 *}$ and Saal L $\mathrm{K}^{2}$ \\ ${ }^{1}$ Professor of Speech-Language-Hearing Sciences, Loyola University Maryland, USA \\ ${ }^{2}$ Associate Professor of Literacy, Loyola University Maryland, USA
}

Submission: February 03, 2021; Published: February 11, 2021

*Corresponding author: Lisa Schoenbrodt, Professor of Speech-Language-Hearing Sciences, Loyola University Maryland, USA

\begin{abstract}
Following the death of a young man with Down Syndrome by law enforcement in Maryland (USA), a statute was passed requiring that all law enforcement officers (LEOs) undergo IDD training approved by the Maryland Police Training Commission. The curriculum utilized by trainers was often lecture-based and provided content knowledge about the characteristics and presentations of people with IDD. While this curriculum was effective in providing information, the lived experiences of members of the community and application-based training were lacking. The authors developed a training model (LEAD) for LEOs using role-play and scenario-based training that includes individuals with IDD as SelfAdvocate Educators (SAE). This model has been delivered to select law enforcement agencies in Maryland. This qualitative case study reports on the Self-Advocate Educators' (SAEs) initial perceptions of their participation in training law enforcement utilizing the LEAD Program Model.

Keywords: Law enforcement; Simulation; Developmental disability; Role-play; Training; Police; Self-advocacy; Communication skills

Abbreviations: LEO: Law Enforcement Officer; SAE: Self-Advocate Educator; IACP: International Association of Chiefs of Police; IDD: Intellectual and/or Developmental Disability; COPS: Community Oriented Policing Services
\end{abstract}

\section{Introduction}

The Community Oriented Policing Services (COPS) Model, established by the U.S. Department of Justice in 1994, encourages law enforcement officers (LEOs) to build relationships with people in the communities they serve. This is especially important for those with communication or behavioral differences resulting from physical, mental, and/or intellectual disability. While estimations of the number of adult persons in the United States who are diagnosed with an intellectual and/or developmental disability (IDD) vary [1], the number of children (age 3-17) diagnosed with IDD has risen to $17 \%$ or one in six [2]. Additionally, individuals with developmental disabilities are seven times more likely to have interactions with law enforcement than nondisabled members of the community [3].

Whether police are called as emergency first responders to provide assistance or investigate criminal activity involving people with intellectual or developmental disabilities, studies have documented that many law enforcement officers either lack training and corresponding vital knowledge and skills to interact with this group or lack confidence in their ability to utilize those skills in practice [4-7]. Often, exposure or empathy training for law enforcement is used to increase sensitivity to and improve interactions with people with IDD. While this method is effective in introducing police officers to the differences in the large and varied population of individuals with IDD, it does not provide the explicit, person centered, communication and problem-solving focused training that is needed [8].

As a result of legislation passed following the death of Ethan Saylor, a young man with Down Syndrome in the custody of law enforcement officers, law enforcement officers in Maryland (USA) must undergo curricular training on working with the IDD population approved by the Maryland Police Training Commission [9]. An approved curriculum must include an evidence-based 
presentation focusing on understanding individuals with IDD/ DD as people first. The curriculum must incorporate information about the various intellectual and developmental disabilities (e.g., Autism, Down Syndrome, Cerebral Palsy) including definitions and characteristics. The curriculum should also contain information about modes of communication and practical ways that law enforcement may effectively engage and communicate with these individuals. The curriculum is often presented in a 3- hour inservice training for current police officers and 8 hours of academy training for new cadets.

While the existing Maryland Police Training Commission classroom training provided the content knowledge on working with individuals with IDD, it lacked the practical application of related skills with individuals who are members of the disability community. Therefore, as a result for a call for demonstration models for including adults with disabilities as trainers from the Ethan Saylor Alliance, the investigators developed a supplementary train-the-trainer training model, the LEAD Program Model, that utilizes individuals with IDD/DD as SelfAdvocate Educators (SAE) and leaders with lived experience in content and scenario-based training. The use of self-advocates as educators and scenario-based training have been shown to be a effective techniques for authentic learning and application of new skills in adult education environments [7-10]. Therefore, the LEAD Program Model was incorporated into the existing training held for law enforcement with the approved curriculum and has been utilized for both veteran police officers and new cadets.

At the end of each LEAD Program Model training, law enforcement participants were surveyed regarding the effectiveness of the training session to increase overall knowledge and application to real-life settings. The data obtained from the sessions provided support for the success of the training. In addition, data was collected from Self-Advocate Educators and their families regarding the impact of participation in the program on communication and self-advocacy skills. This qualitative case study [11] reports on the initial perceptions of the Self-Advocate Educators (SAEs) participation in the LEAD Program Model outlined above. This study attempted to answer the question, “What are the Self-Advocate Educators' perceptions of participating in the LEAD Program Model of training for law enforcement?"

\section{Methods}

Ten Self-Advocate Educators (SAE) ranging in age from 18 to 41 with a variety of intellectual and developmental disabilities (IDDs) participated in five train-the-trainer training sessions where they learned to hone and expand their communication and self-advocacy skills using improvisational acting techniques. Improvisational acting techniques were used primarily for SAE training on the scenarios-based modules because behavioral and communication training interactions needed to be as authentic as possible for learning transfer for the law enforcement officers. Following these skill-based trainings, the SAE's participated in 5 in-person trainings with law enforcement officers (LEOs) where they engaged directly with veteran police officers and cadets.

\section{a. Data Collection/Analysis}

Three data sources were utilized in this case study. First, at the conclusion of all the training sessions, all ten (10) Self-Advocate Educators (SAEs) were distributed a qualitative questionnaire to gain insights from the SAEs on their experiences with both the LEAD Program curriculum and participating in their roles as police trainers. The qualitative questionnaire contained eight openended response questions and one yes/no question which sought to solicit perspectives from the trainees on their experiences with both the LEAD Program curriculum and their participation in police training. The instrument included questions like: "What made you want to be a LEAD Self-Advocate Educator (SAE)?" and "How would you describe your experience as an SAE to someone else?"

Next, follow up interviews with the SAEs and their families were also conducted to both clarify or expand on responses and member check for validity. Finally, documents including lesson plans, anecdotal records, and the field notes of the researchers were used as an additional source of data for the study. All data sources were analyzed using the constant comparative method [12] whereby incidents derived from the participants' responses were coded into categories and subsequent themes.

\section{Results/Discussion}

In attempting to answer the question, "what are the SelfAdvocate Educators' perceptions of participating in the LEAD Program Model of training for law enforcement?" three themes emerged following analysis. These were Self-Advocate Educators perceptions of: 1) law enforcement's use of person-first language and interactions, 2) law enforcement's increased understanding of the range of abilities of people with IDD, and 3) the role of relationship building through training.

First, Self-Advocate Educators (SAEs) impressed upon the researchers their increased awareness of LEOs' use of personfirst language and and communication skill during the training. While many SAEs had previous interactions with LEOs in their community, they recognized their training role as enhancing the language, communication, and behaviors of LEO. While many SAEs had previous interactions with law enforcement officers in the community, their role as SAEs provided participants with added insight on their role in LEAD Program Model training as enhancing the language and communication skill of LEO trainees. For example, one SAE commented, "[During trainings], I observed the police officers employ unique methods of personally connecting with individuals. I never would have presumed."

Additionally, Self-Advocate Educators (SAEs) perceived a shift in participating law enforcement Officers' understanding of the range of communication and behavioral abilities (and corresponding assets and needs) of people with intellectual 
and developmental disabilities. Multiple SAEs with significant differences in both communication and affect often participated in the same training with LEOs. SAEs were often aware of not only the impact of their own presentations, but their co-trainers and fellow SAEs as well. As an exemplar, a Self-Advocate Educator offered that his participation in LEAD Program Model trainings helped to increase pre-service and in-service officers' communication abilities "because I can help them learn to understand people who talk like me. I know what I want to say, but they might think that I don't because I sound different."

Finally, Self-Advocate Educators (SAEs) articulated their perceptions of their importance and unique contribution as relationship builders in the LEAD Program Model trainings. Several spoke of the opportunity to engage in relationship building with law enforcement officers in the SAE role as a pivotal contribution to their local community. One SAE explained saying, "[participating in the LEAD Program Model training] was important for me to help the policemen because they might not know someone has special needs and be mean to them." The reciprocal nature of their participation as trainers and subsequent relationship building was also highlighted. "My role as a SAE can develop healthy relationships between people with IDD and police officers." In responses like the one above, SAEs mentioned how their participation in teaching law enforcement officers could lead to better outcomes for people with disabilities who interact with law enforcement.

In addition to the SAEs family members were asked to provide feedback on their perceptions of their SAEs participation in the LEAD Model. Across the dataset, family members' perceptions largely matched and/or reinforced the responses of the SAEs themselves. However, family members also added an unexpected, additional theme. Family members reported that they perceived an increase in the daily communication abilities of the SAE in their family after participating in the LEAD Model trainings. Comments such as, 'we can't believe how much better she is communicating," " he's so much better at self-advocating," and "she's so much more comfortable and confident in front of people" were common across family member responses. Further, the LEAD Model trainers, the authors of this study anecdotally also noted that, overall, the SAEs increased their level of confidence in speaking to a group of people they did not know. In addition, most SAEs' communication abilities improved in overall intelligibility of speech, in the number of words and type of vocabulary used, in understanding and displaying complex emotional behaviors and responses, and in maintaining and continuing conversational exchanges.

\section{Conclusion}

The purpose of this study was to identify Self-Advocate Educators' perceptions of participating in the LEAD Program Model of training for law enforcement. Participants articulated their belief in importance and efficacy of SAEs, as members of the community and people with lived experience, "leading the way" in trainings regarding effective interactions between law enforcement and people with intellectual and developmental disabilities. As a result of the findings of this study, further research will be conducted to measure the impact of participating as a LEAD Program Model Self-Advocate Educator on the communication skills and self-reported self-efficacy of participants [13].

\section{References}

1. Anderson LL, Larson SA, MapelLentz S, Hall-Lande J (2019) A Systematic Review of U.S. Studies on the Prevalence of Intellectual or Developmental Disabilities Since 2000. Intellectual and Developmental Disabilities 57(5): 421-438.

2. Zablotsky B, Black L I, Maenner M J, Schieve LA, Danielson ML, et al. (2019) Prevalence and Trends of Developmental Disabilities among Children in the United States: 2009-2017. Pediatrics 144(4): e20190811.

3. Organization for Autism Research (2014) Life Journey Through Autism: A Guide to Safety (pp 1-131). Organization for Autism Research.

4. Gardner L, Campbell JM, Westdal J (2019) Brief Report: Descriptive Analysis of Law Enforcement Officers' Experiences with and Knowledge of Autism. Journal of Autism and Developmental Disorders 49(3): 1278-1283.

5. Gulati G, Kelly BD, Cusack A, Kilcommins S, Dunne CP (2020) The experience of law enforcement officers interfacing with suspects who have an intellectual disability - A systematic review. International Journal of Law and Psychiatry 72: 101614.

6. Railey KS, Love AMA, Campbell JM (2020) A Systematic Review of Law Enforcement Training Related to Autism Spectrum Disorder. Focus on Autism and Other Developmental Disabilities 35(4): 221-233.

7. Silverstone PH, Krameddine YI, DeMarco D, Hassel R (2013) A novel approach to training police officers to interact with individuals who may have a psychiatric disorder. Journal of the American Academy of Psychiatry and the Law 41(3): 344-355.

8. IACP Law Enforcement Policy Center (2017) Interactions with Individuals with Intellectual and Developmental Disabilities Model Policy Concepts \& Issues Paper Need to Know.... IACP Law Enforcement Policy Center.

9. Shank C (2015) Commission for Effective Community Inclusion of Individuals with Intellectual and Developmental Disabilities (pp. 1-17). Maryland Governor's Office of Crime Control and Prevention.

10. Simplican SC (2015) The capacity contract: Intellectual disability and the question of citizenship. (UMCP McKeldin Library HV3004. S542015). University of Minnesota Press; USMAI Catalog.

11. Stake RE (1995) The art of case study research. Sage.

12. Glaser B, Strauss A (1967) The discovery of grounded theory: Strategies for qualitative research. Mill Sociology Press.

13. Office of Community Oriented Policing Services (2014). Community Policing Defined (No. 157; p. 16). U.S. Department of Justice. 
This work is licensed under Creative Commons Attribution 4.0 License

DOI: 10.19080/GJIDD.2021.07.555718
Your next submission with Juniper Publishers will reach you the below assets

- Quality Editorial service

- Swift Peer Review

- Reprints availability

- E-prints Service

- Manuscript Podcast for convenient understanding

- Global attainment for your research

- Manuscript accessibility in different formats

( Pdf, E-pub, Full Text, Audio)

- Unceasing customer service

Track the below URL for one-step submission https://juniperpublishers.com/online-submission.php 